\title{
Cost of Deliveries among Health Insurance (HI) Enrollees and Out-of- Pocket (OOP) Payers Accessing Maternal Healthcare Services in a Tertiary Health Institution in Southwest Nigeria
}

\author{
Taofeek Adedayo Sanni ${ }^{1,2^{*}}$, Ebenezer Obi Daniel ${ }^{3}$, Babatunde Aderukuola ${ }^{4}$ \\ ${ }^{1}$ Department of Community Medicine, Federal Teaching Hospital Ido-Ekiti, Ekiti State, \\ Nigeria \\ ${ }^{2}$ Texila American University, Guyana, South America \\ ${ }^{3}$ World Health Organization (WHO) - Nigeria \\ ${ }^{4}$ Department of Obstetrics and Gynecology, Federal Teaching Hospital Ido-Ekiti, Ekiti State, \\ Nigeria
}

\begin{abstract}
Maternal mortality is currently high and remains one of the most important public health problems in developing countries. This study determined the cost of vaginal and caesarean section deliveries among Health Insurance (HI) enrollees and Out-of-Pocket (OOP) payers. A comparative crosssectional study was carried out among 380 women \{(133 vaginal and 57 caesarean section deliveries among each of HI enrollees and OOP payers)\} who accessed delivery services in a tertiary health institution in Southwest Nigeria using a systematic random sampling technique. Data was gathered using an interviewer-administered semi-structured questionnaire and analyzed using IBM SPSS version 23. P-value <0.05 was taken as significant. The overall mean age of respondents in this study was $36.5 \pm 4.7$ years among the vaginal delivery respondents and $35.8 \pm 3.6$ years among caesarean

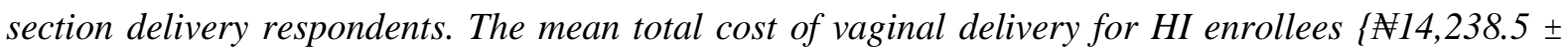
4,809.0 (\$34.5 \pm 12.7$)\}$ is lesser than for OOP payers $\{\$ 37,928.5 \pm 19,813.0(\$ 99.8 \pm 52.1)\}$. Furthermore, the mean total cost of caesarean section delivery for HI enrollees $\{14,238.5 \pm 4,809.0$ $(\$ 34.5 \pm 12.7)\}$ is lesser than for OOP payers ( $\$ 37,928.5 \pm 19,813.0(\$ 99.8 \pm 52.1) .94 .1 \%$ of the non-insurance enrollees were willing to join Health Insurance Scheme. It was concluded that the total cost of vaginal and caesarean section deliveries is lower among the Health Insurance enrollees than the Out-of-Pocket payers. Therefore, intervention to increase awareness on health insurance is recommended.
\end{abstract}

Keywords: Cost, caesarean section delivery, Health insurance enrollees, Vaginal delivery, Out-ofPocket payers.

\section{Introduction}

Maternal mortality is currently high, remains one of the most important public health problems in developing countries and an issue of concern on the international health agenda $[1,2]$. Maternal mortality remains high in many developing countries, and the difference in maternal mortality between developed higherincome and lower-income countries is greater than any other mortality rate. The death of women during childbirth is the greatest immoral global inequality as most deaths in childbirth are preventable [2]. Maternal mortality is the leading cause of death and premature disability for women of reproductive age groups in developing countries [2].

Nigeria contributes about $10 \%$ of the global maternal maternity burden despite having just $2 \%$ of the global population [3]. Annually about 
52,900 Nigerian women die (about 1,000 per week) in pregnancy, during childbirths, or within the 42days of giving birth out of the global 529,000 women [3]. This number is equivalent to an aircraft with full of Nigerian mothers crashing with no survivor on a daily basis for an entire year [3, 4].

Even with high maternal morbidity and mortality rates, maternal healthcare services still require spending out of pocket, and many people who genuinely require these services do not usually have access to them [5]. Apart from indirect costs, maternal healthcare services include the cost of antenatal investigations, procurement of drugs, and cost of deliveries which varies whether it is a vaginal delivery (VD) or caesarean section delivery (CSD). Cost for maternal care is a major contributor to households' expenses and a major barrier to the utilization and access to safe maternal care [3].

According to the World Health Organization report, people in most low-income countries pay a high proportion of their health costs directly to health-care providers through Outof-Pocket [6,7]. High cost is a hindrance to basic healthcare in many developing countries. Also, with households paying out-of-pocket (OOP) for most healthcare services received and expending a higher proportion of their income on private healthcare expenditures, there will be attending catastrophic consequences on the family's financial wellbeing [8].

Health insurance strategies are designed to bring about an improvement in overall maternal and child health via different direct and indirect routes. Directly, this can be achieved by reducing OOP expenses for healthcare services, thereby facilitating timely use of healthcare and access to maternal health services [9]. Availability of health insurance in developing nations is expected to decrease healthcare spending and make more money available for households' expenditure on other needs, especially nutritious foods [9].
Nigeria made legislation on health insurance in 1999 couldn't commence the programme until 2005, and up to date, less than $10 \%$ of the population have enrolled into the scheme, with over $90 \%$ of country populations still paying out of pocket [8]. This has contributed to the country's inability to effectively address her numerous public health challenges with associated weakness of the health system due to catastrophic health expenditure and high poverty level due to out-of-pocket payment for health care services that are unaffordable $[10$, 11].

The expenses incurred during childbearing varied with the place of antenatal care (ANC) services. The cost of vaginal delivery in Australian state Queensland between July 1, 2012, and June 30, 2015, showed that the cost of delivery was $\$ 623( \pm 1202)$ for women who gave birth in private and public hospitals, respectively. Total fees for women who had a vaginal birth without instrumentation were (\$556 [ \pm 1044$]$ and \$2560 [ \pm 2284$])$ in both settings [12]. The cost estimate of normal vaginal delivery is U\$140.41 for Argentina. Costs are significantly lower at the health centre compared to the hospital level [13].

Normal delivery in a health care facility in Nepal was US\$64. For Bangladesh, these costs were US $\$ 85$ and US\$181 [14]. In a study done in Rajasthan, India, OOP expenditure in public health centres was US $\$ 44$ and US $\$ 145$ for normal and complicated delivery, respectively [15]. In a study to determine the cost of vaginal delivery and caesarean section in Pakistan, the average cost of vaginal delivery was to be $\$ 40$ [16]. Another study documented vaginal delivery incurred costs of US\$12.52 to US\$20.64 in Ghana, US\$0.35 to US\$7.86 in Malawi, and US\$2.20 to US\$22.75 in Uganda [17].

In Nigeria, according to a study done in a rural community of Kaduna State, Nigeria, the average amount spent on vaginal delivery is $\$ 9.6$, while Antenatal care plus vaginal delivery 
costs \$22 [3]. Another study done in Ado-Ekiti documented a mean cost of $\$ 52,475.9 \pm 4425.7$ (\$131.2 $\pm \$ 11.1)$ for public hospitals and N95224.1 $\pm 10,653.4(\$ 238 \pm \$ 26.6)$ for private [18].

In Australia, the cost of caesarean section averaged (\$716 [ \pm 1419$]$ [12]. The cost per caesarean delivery in Nepal is US\$129 [15] while in Bangladesh, the self-reporting cost of caesarean delivery in a study determinant of out-of-pocket payments on child delivery care was $\$ 249.8 \pm 153.54$ [19]. In a study to determine the cost of vaginal delivery and caesarean section in Pakistan, the average cost of caesarean section was to be $\$ 162$ [16]. In Rwanda, the average cost of caesarean section delivery is $\$ 339$ ( $\$ 320$ to $\$ 380$ ) for out-ofpocket payers, while for those under health insurance, the co-payment was \$34 [20].

In a comparative analysis of caesarean delivery among Out-of-Pocket and Health Insurance clients in Ilorin, Nigeria, the cost of caesarean section among 93\% of OOP respondents is between USD 351-500, while $90 \%$ of those on health insurance paid less than USD 300 [7]. Another study done among women in Ado-Ekiti, Ekiti State documented a mean cost of $\$ 90,673.9 \pm 9,199.5$ (\$226.7 \pm \$23) for caesarean section in public hospitals and $\$ 205,765 \pm 17339.7$ (\$514.4 $\pm \$ 43.3$ ) for private [18].

\section{Methodology}

This survey is a comparative cross-sectional study carried out among 380 women \{(133 vaginal and 57 caesarean section deliveries among HI enrollees and (133 vaginal and 57 caesarean section deliveries among OOP payers) $\}$ who accessed delivery services in a tertiary health institution in Southwest Nigeria. Ekiti State, which is one of the thirty-six states in Nigeria, is located in the southwestern part of the country. The State was carved out of the old Ondo State in October 1996 with the headquarters located in Ado-Ekiti. It has three senatorial districts (Ekiti Central, Ekiti South, and Ekiti North senatorial districts. Ekiti Central and Ekiti North) divided into sixteen (16) Local Government Areas (LGAs). Ekiti State has an estimated total population of 2,384,212 (National Population Commission figures of 2006) with a 2021 projection of $3,816,784$ based on an annual growth rate of 3.2\% [21]. Federal Teaching Hospital Ido-Ekiti is a Federal Government of Nigeria-owned Tertiary health Institution located in Ekiti State, South West region of Nigeria. The hospital was established in 1954 as a General Hospital but was changed to Federal Medical Centre IdoEkiti in the year 1988 and later to a Teaching Hospital by 2014. The hospital offers undergraduate and postgraduate medical training. It serves as a referral center for all other health institutions such as general hospitals, specialist centres, and comprehensive health centres in Ekiti state [22].

The study populations were women accessing maternal health services (delivery) at Federal Teaching Hospital, Ido-Ekiti, and respondents were selected using a systematic random sampling technique. Data was gathered using an interviewer-administered semistructured questionnaire between September 2020 and February 2021. The content of the questionnaire was adapted from the World Bank Living Standard Measurement Survey [6, 23]. The questionnaire has four sections that assessed the socio-demographic characteristics, cost of vaginal delivery, cost of caesarean section delivery, and willingness of noninsurance enrollees to take up health insurance. This instrument was assessed by public health experts and epidemiologists from Federal Teaching Hospital, Ido-Ekiti. It was tested for internal validity using a reliability test, and Cronbach's alpha coefficient of 0.80 was gotten.

Data collected were analyzed using IBM SPSS version 23. Costs of vaginal and caesarean section deliveries were the dependent variable, and these were obtained in Naira and also converted to US Dollar equivalent using 
the Central Bank of Nigeria foreign exchange rate of $\$ 380$ to $\$ 1$ as at April 2021. This was done to enable comparability with studies outside the country. Frequency, percentages, mean and standard deviation were presented in tables at the univariate level of analysis. Chisquare and binary logistic regression were used to assess the association between dependent and independent variables at bivariate and multivariate levels of analysis, respectively. Pvalue $<0.05$ was taken as significant.

Ethical approval was sought and obtained from the Human Ethics and Research Committee of Federal Teaching Hospital, IdoEkiti, Ekiti State, Nigeria. Participation was anonymous and voluntary. Informed consent was taken by ticking a yes/no question.

\section{Results}

\section{Socio-demographic Characteristics}

A total of 260 vaginal delivery respondents (130 for $\mathrm{HI}$ and 130 for OOP) and 99 caesarean section delivery respondents ( 54 for $\mathrm{HI}$ and 55 for OOP) participated in the study.

Table 1 shows the socio-demographic characteristics of the vaginal delivery respondents. The overall mean age of the respondents who had normal vaginal delivery was $36.5 \pm 4.7$. However, the mean age of the OOP group $(37.3 \pm 4.2)$ is slightly higher than the HI group $35.7 \pm 5.0$, and this difference is statistically significant $(\mathrm{p}=0.005)$. About $5.4 \%$ of respondents in the OOP group who had vaginal delivery were unmarried mothers as against none among the HI group. About half of the HI enrollees have a family size of five and above as against three quarter among the OOP payers with a statistical difference of $p<0.001$. $23.1 \%$ of the $\mathrm{HI}$ enrollee who accessed normal vaginal delivery lives in the rural area, and this is more than $3.8 \%$ of respondents among OOP payers. This difference in the area of residence is statistically significant at $\mathrm{p}<0.001$. More (63.1\%) HI enrollees who accessed delivery services have tertiary education as against $53.1 \%$ among the OOP payers, and this difference is statistically significant at $\mathrm{p}<0.004$. About two-thirds of respondents who delivered via normal vaginal delivery are civil servants in the HI group, while about the same proportion in the OOP group were professionals. This difference in occupation across the two groups is statistically significant at $\mathrm{p}<0.001$.

Table 2 shows the socio-demographic characteristics of the caesarean section delivery respondents. The overall mean age of the respondents who had caesarean section delivery was $35.8 \pm 3$.6years. However, the mean age of OOP group ( $36.0 \pm 3.7$ years) is slightly higher than the HI group $35.7 \pm 3.4$ years, and this difference is not statistically significant $(\mathrm{p}=$ 0.684). A very low percentage (3.7\%) of the HI enrollee who had caesarean delivery lives in the rural area as against is more than $45.5 \%$ of respondents among OOP payers. This difference in the area of residence is statistically significant at $p<0.001$. Almost all $(96.3 \%)$ of HI enrollees who had caesarean delivery have tertiary education as against only two fifth (40\%) among the OOP payers, and this difference is statistically significant at $\mathrm{p}<0.001$. About two-thirds of respondents who delivered via caesarean section are civil servants in the $\mathrm{HI}$ group as against the trader majority in the OOP group. This difference in occupation across the two groups is statistically significant at $\mathrm{p}<$ 0.001 . None of the respondents who delivered via caesarean section earn less than $\$ 30,000$ national minimum wage of the country while about two-fifth of their OOP counterparts still earn less than the $\$ 30,000$ national wage benchmark; this difference is statistically significant at $\mathrm{p}<0.001$. Also, the median income of the HI group $\{\$ 160,000(\$ 64,000)\}$ is much higher than the OOP group $\{60,000$ ( 40,000$)\}$ and this difference is statistically significant $(\mathrm{p}=<0.001)$.

\section{Cost of Vaginal Delivery}

The mean total cost of Vaginal Delivery (VD) among HI enrollees (14,238.5 \pm 4,809.0 equivalent to $\$ 34.5 \pm 12.7$ ) is lesser than the 
mean cost for OOP payers (\$37,928.5 \pm $19,813.0$ equivalent to $\$ 99.8 \pm 52.1$ ). This difference is statistically significant. Worth nothing is the fact that, this difference in cost is majorly due to the difference indirect cost of VD services between the two groups $\{\mathrm{HI}$ : $\$ 7,304.6 \pm 2,791.9(\$ 19.2 \pm 7.4)$ vs OOP: $\$ 30,650.8 \pm 18,838.3((\$ 80.6 \pm 49.6)\}$, because indirect cost in both group is almost similar $\{\mathrm{N} 6,933.8 \pm 3,517.5(\$ 18.2 \pm 9.3)$ vs $\$ 7,277.7$ $\pm 4,920.6(\$ 19.2 \pm 12.9)\}$.

\section{Cost of Caesarean Section Delivery}

The mean total cost of Caesarean Section Delivery (CSD) as found in this study among $\mathrm{HI}$ enrollees is $\$ 33,775.9 \pm 10,967.5$ (equivalent to $\$ 88.9 \pm 28.9$ ) and this is lesser than the mean total cost for OOP payers $\$ 98,570.9 \pm 58,349.3$ (equivalent to $\$ 259.4 \pm$ 153.6). This higher cost in OOP group occurred for both direct $\{\mathrm{HI}$ : $\$ 21,122.2 \pm 8,160.3$ (\$55.6 \pm 21.5 ) vs OOP: $\$ 82,381.8 \pm 53,656.5$ (\$216.8 $\pm 141.2)\}$ and indirect cost $\{\mathrm{HI}: 112,653.7 \pm$ $7,207.9$ (\$33.3 \pm 19.0$) *$ vs OOP: $16,189.1 \pm$ $10,432.1(\$ 42.6 \pm 27.5)$.

\section{Willingness to take up Health Insurance by non-enrollees}

A large majority (94.1\%) of the Out-ofPocket respondents (non-insurance enrollee) in this study were willing to now join the Health Insurance Scheme. However, about three quarters of these women want to discuss this with their family before doing so. this may affect their eventual enrolment if the husband is unwilling and do not believe in the scheme. Of the little population (5.9\%) of the OOP respondents in this study who are unwilling to join Health Insurance, half of them took such position because they could not afford the money for premium payment.

\section{Discussion}

The overall mean age of vaginal delivery respondents in this study is $36.5 \pm 4$.7years. However, the mean age of Out-of-Pocket (OOP) group (37.3 \pm 4.2 years) is slightly higher than the Health Insurance (HI) group (35.7 \pm 5.0 years). Likewise, the overall mean age of caesarean section delivery was $35.8 \pm$ 3.6year with the mean age of the OOP group $(36.0 \pm 3.7$ years) slightly higher than the HI group $35.7 \pm 3.4$ years. As found in this study, these mean ages of respondents are within the age normal range of women of reproductive age group (18 - 49 years), which is expected in a study to assess the cost of maternal healthcare services. This study finding is close to what was documented in a comparative analysis of Caesarean Delivery among and Health Insurance client in Ilorin, Nigeria where mean ages of 31.93 years and 31.37 years were documented for Health Insurance client and Out-of-Pocket payers' respectively [7]. This may be due to closeness in the marriage culture of both areas. However, this study finding is higher than in a study on the influence of Health Insurance on utilization of maternal healthcare services in Kunda Health District, where the mean age of $29.16 \pm 6.25$ years was reported [24]. It is also higher than as reported by the Vietnam study, where mean ages of 27.2years and 27.0 years were documented for Health Insurance and Out-of-Pocket clients, respectively, in a related study done in Vietnam [25]. This difference might be due to cultural differences in age of marriage and childbirth. Though the high mean age of women accessing maternal healthcare services in this study is good as matured mothers tend to have better understanding, education, and maternal outcome, it may also not be too good as teratology increases with increase maternal age.

The mean total cost of Vaginal Delivery (VD) among HI enrollees ( $14,238.5 \pm 4,809.0$ equivalent to $\$ 34.5 \pm 12.7$ ) is lesser than the mean cost for OOP payers ( $\$ 37,928.5 \pm$ $19,813.0$ equivalent to $\$ 99.8 \pm 52.1)$. This difference is statistically significant. Worth nothing is the fact that, this difference in cost is majorly due to the difference in direct cost of VD services between the two groups (HI$\$ 7,304.6 \pm 2,791.9(\$ 19.2 \pm 7.4)$ vs OOP - 
\#30,650.8 $\pm 18,838.3$ ( $(\$ 80.6 \pm 49.6)\}$, because indirect cost in both group is almost similar $\{\$ 6,933.8 \pm 3,517.5(\$ 18.2 \pm 9.3)$ vs $\$ 7,277.7$ $\pm 4,920.6(\$ 19.2 \pm 12.9)\}$. Also, this difference might be due to the fact that the HI enrollees pay only a small percentage of their direct healthcare cost (co-insurance) on most services. This finding ( $\$ 34.5$ for $\mathrm{HI}$ and $\$ 99.8$ for OOP) is higher than the findings among $\mathrm{HI}$ and OOP clients in a study on affordability and healthseeking behaviour for delivery and ANC among poor and ethnic minority in rural Vietnam where \$24.2 for $\mathrm{HI}$ and $\$ 66.1$ for OOP vaginal deliveries was documented [25]. The OOP cost of payment in this study is also higher than the OOP cost of delivery in tertiary level hospital in Islambad, Pakistan, and in a study on OOP cost of vaginal delivery in Bangladesh where the cost of $\$ 77$ and $\$ 79.23$, respectively was reported $[16,19]$. The OOP cost in this study is, however similar to the $\$ 99$ OOP cost of delivery in hospitals in Uttar Pradesh, India [26] but lower than finding in another study done in Ado-Ekiti, Ekiti State where a cost of $\$ 52,475.9 \pm 4425.7$ (\$131.2 \pm 11.1$)$ was found [18].

The mean total cost of Caesarean Section Delivery (CSD) as found in this study among $\mathrm{HI}$ enrollees is $\$ 33,775.9 \pm 10,967.5$ (equivalent to $\$ 88.9 \pm 28.9$ ), and this is lesser than the mean total cost for OOP payers ( $\$ 98,570.9 \pm 58,349.3$ equivalent to $\$ 259.4 \pm$ 153.6). This higher cost in OOP group occurred for both direct $\{\mathrm{HI}-\mathrm{N} 21,122.2 \pm 8,160.3$ (\$55.6 $\pm 21.5)$ vs OOP - $82,381.8 \pm 53,656.5(\$ 216.8$ $\pm 141.2)\}$ and indirect cost $\{\mathrm{HI}-\mathrm{N12,653.7 \pm}$ $7,207.9(\$ 33.3 \pm 19.0)$ vs OOP $-\$ 16,189.1 \pm$ $10,432.1(\$ 42.6 \pm 27.5)$. The differences in direct, indirect, and total cost are statistically significant. The difference in the direct cost might be due to the payment of a small percentage of direct healthcare cost (coinsurance) by $\mathrm{HI}$ enrollees, while the difference in indirect cost might be due to shorter hospital stays. This finding (\$88.9 for HI and \$259.4 for OOP) is close to as documented in a study in Vietnam ( $\$ 111.3$ for $\mathrm{HI}$ and $\$ 224.8$ for OOP) and in another study in Rural District Hospital in Rwanda ( $\$ 34$ for HI and \$339 for OOP) [20, 25]. The OOP payment on Caesarean Section Delivery in this study is also similar to as reported in another Ekiti State study where \$226 \pm \$23 was documented and a study in Bangladesh where $\$ 249.8$ was found $[18,19]$. This study finding is lower than the result found in Ilorin, Nigeria, where more than $90 \%$ of the HI clients paid $<\$ 300$ and more than $90 \%$ of the OOP clients paid between $\$ 350$ and $\$ 500$ for Caesarean Section Delivery [7]. The finding is however lower than the OOP cost of Caesarean delivery in Australia (average in public hospitals; \$719) [12].

A large majority (94.1\%) of the Out-ofPocket respondents (non-insurance enrollee) in this study were willing to now join the Health Insurance Scheme. However, about three quarters of these women wants to discuss this with their family before doing so. This may affect their eventual enrolment if the husband is unwilling and does not believe in the scheme of the little population $(5.9 \%)$ of the OOP respondents in this study who are unwilling to join Health Insurance, half of them took such position because they could not afford the money for premium payment. 
Table 1. Socio-demographic Characteristics of Normal Delivery Respondents (Compared between the HI Enrollees and OOP Payers)

\begin{tabular}{|c|c|c|c|c|c|}
\hline \multirow[t]{2}{*}{ Variable } & $\begin{array}{l}\text { Health Insurance } \\
\text { Enrollee- n (130) } \\
\end{array}$ & $\begin{array}{l}\text { Out-of-Pocket } \\
\text { Payer- n (130) }\end{array}$ & Total $N=260$ & \multirow[t]{2}{*}{$\chi^{2}$} & \multirow[t]{2}{*}{ P-value } \\
\hline & $(\%)$ & $(\%)$ & $\mathbf{N}(\%)$ & & \\
\hline \multicolumn{6}{|l|}{ Age group (in years) } \\
\hline $15-24$ & $2(1.5)$ & $0(0.0)$ & $2(0.8)$ & \multirow[t]{3}{*}{3.968} & \multirow[t]{3}{*}{0.138} \\
\hline $25-34$ & $50(38.5)$ & $40(30.8)$ & $90(34.6)$ & & \\
\hline 35 and above & $78(60.0)$ & $90(69.2)$ & $168(64.6)$ & & \\
\hline Mean age \pm SD & $35.7 \pm 5.0$ & $37.3 \pm 4.2$ & $36.5 \pm 4.7$ & -2.847 & 0.005 \\
\hline \multicolumn{6}{|l|}{ Marital Status } \\
\hline Married & $130(100.0)$ & $123(94.6)$ & $253(97.3)$ & \multirow[t]{2}{*}{7.194} & \multirow[t]{2}{*}{0.007} \\
\hline Not married & $0(0.0)$ & $7(5.4)$ & $7(2.7)$ & & \\
\hline \multicolumn{6}{|c|}{ Family type $(n=253)$} \\
\hline Monogamy & $104(80.0)$ & $121(98.4)$ & $225(88.9)$ & \multirow[t]{2}{*}{21.679} & \multirow[t]{2}{*}{$<0.001$} \\
\hline Polygamy & $26(20.0)$ & $2(1.6)$ & $28(11.1)$ & & \\
\hline \multicolumn{6}{|l|}{ Family size } \\
\hline$<5$ & $66(50.8)$ & $34(26.2)$ & $100(38.5)$ & \multirow[t]{2}{*}{16.640} & \multirow[t]{2}{*}{$<0.001$} \\
\hline$\geq 5$ & $64(49.2)$ & $96(73.8)$ & $160(61.5)$ & & \\
\hline \multicolumn{6}{|l|}{ Religion } \\
\hline Christianity & $86(66.2)$ & $98(75.4)$ & $184(70.8)$ & \multirow[t]{2}{*}{2.677} & \multirow[t]{2}{*}{0.102} \\
\hline Islam & $44(33.8)$ & $32(24.6)$ & $76(29.2)$ & & \\
\hline \multicolumn{6}{|l|}{ Ethnicity } \\
\hline Yoruba & $116(89.2)$ & $89(68.5)$ & $205(78.8)$ & \multirow[t]{2}{*}{16.811} & \multirow[t]{2}{*}{$<0.001$} \\
\hline Others & $14(10.8)$ & $41(31.5)$ & $55(21.1)$ & & \\
\hline \multicolumn{6}{|c|}{ Locality of residence } \\
\hline Rural & $30(23.1)$ & $5(3.8)$ & $35(13.5)$ & \multirow[t]{3}{*}{22.057} & \multirow[t]{3}{*}{$<0.001$} \\
\hline Semi-urban & $60(46.2)$ & $65(50.0)$ & $125(48.1)$ & & \\
\hline Urban & $40(30.7)$ & $60(46.2)$ & $100(38.5)$ & & \\
\hline \multicolumn{6}{|l|}{ Educational level } \\
\hline Primary & $22(16.9)$ & $12(9.2)$ & $34(13.1)$ & \multirow[t]{3}{*}{11.114} & 0.004 \\
\hline Secondary & $26(20.0)$ & $49(37.7)$ & $75(28.8)$ & & \\
\hline Tertiary & $82(63.1)$ & $69(53.1)$ & $151(58.1)$ & & \\
\hline Main occupation & & & & & \\
\hline Trader & $20(15.4)$ & $46(35.4)$ & $66(25.4)$ & 67.365 & $<0.001$ \\
\hline Farmer & $14(10.8)$ & $5(3.8)$ & $19(7.3)$ & & \\
\hline Artisan/ technician & $18(13.8)$ & $9(6.9)$ & $27(10.4)$ & & \\
\hline Civil servant & $54(41.6)$ & $10(7.7)$ & $64(24.6)$ & & \\
\hline Professional & $22(16.9)$ & $60(46.2)$ & $82(31.5)$ & & \\
\hline Unemployed & $2(1.5)$ & $0(0.0)$ & $2(0.8)$ & & \\
\hline Monthly income (I) & & & & & \\
\hline$<30,000$ & $45(34.6)$ & $52(40.0)$ & $97(37.3)$ & 0.806 & 0.369 \\
\hline$\geq 30,000$ & $85(65.4)$ & $78(60.0)$ & $163(62.7)$ & & \\
\hline $\begin{array}{l}\text { Median income } \\
\text { (IQR) }\end{array}$ & $100000(112500)$ & $110000(13000)$ & $110000(130000)$ & $7834.500 *$ & 0.307 \\
\hline
\end{tabular}

*Mann-Whitney U test 
Table 2. Socio-demographic Characteristics of Caesarian Section Delivery Respondents (Compared between the HI Enrollees and OOP Payers)

\begin{tabular}{|c|c|c|c|c|c|}
\hline \multirow[t]{2}{*}{ Variable } & $\begin{array}{l}\text { Health Insurance } \\
\text { Enrollee- n (54) }\end{array}$ & $\begin{array}{l}\text { Out-of-Pocket } \\
\text { Payer- n (55) } \\
\end{array}$ & Total $N=109$ & \multirow[t]{2}{*}{$\chi^{2}$} & \multirow[t]{2}{*}{$P=$ Value } \\
\hline & $(\%)$ & $(\%)$ & $\mathbf{N}(\%)$ & & \\
\hline \multicolumn{6}{|l|}{ Age group (in years) } \\
\hline $25-34$ & $25(46.3)$ & $19(34.5)$ & $44(40.4)$ & \multirow[t]{2}{*}{1.563} & \multirow[t]{2}{*}{0.211} \\
\hline 35 and above & $29(53.7)$ & $36(65.5)$ & $65(59.6)$ & & \\
\hline Mean age \pm SD & $35.7 \pm 3.4$ & $36.0 \pm 3.7$ & $35.8 \pm 3.6$ & -0.408 & 0.684 \\
\hline \multicolumn{6}{|l|}{ Marital Status } \\
\hline Married & $54(100.0)$ & $55(100.0)$ & $109(100.0)$ & $*$ & $*$ \\
\hline \multicolumn{6}{|l|}{ Family type $(n=109)$} \\
\hline Monogamy & $53(98.1)$ & $53(96.4)$ & $106(97.2)$ & \multirow[t]{2}{*}{0.324} & \multirow[t]{2}{*}{0.569} \\
\hline Polygamy & $1(1.9)$ & $2(3.6)$ & $3(2.8)$ & & \\
\hline \multicolumn{6}{|l|}{ Family size } \\
\hline$<5$ & $29(53.7)$ & $21(38.2)$ & $50(45.9)$ & \multirow[t]{2}{*}{2.644} & \multirow[t]{2}{*}{0.104} \\
\hline$\geq 5$ & $25(46.3)$ & $34(61.8)$ & $59(54.1)$ & & \\
\hline \multicolumn{6}{|l|}{ Religion } \\
\hline Christianity & $37(68.5)$ & $30(54.5)$ & $67(61.5)$ & \multirow[t]{2}{*}{2.246} & \multirow[t]{2}{*}{0.134} \\
\hline Islam & $17(31.5)$ & $25(45.5)$ & $42(38.5)$ & & \\
\hline \multicolumn{6}{|l|}{ Ethnicity } \\
\hline Yoruba & $50(92.6)$ & $27(49.1)$ & $77(70.6)$ & \multirow[t]{2}{*}{24.863} & \multirow[t]{2}{*}{$<0.001$} \\
\hline Others & $4(7.4)$ & $28(50.9)$ & $32(29.4)$ & & \\
\hline \multicolumn{6}{|l|}{ Locality of residence } \\
\hline Rural & $2(3.7)$ & $25(45.5)$ & $27(24.8)$ & \multirow[t]{3}{*}{28.616} & \multirow[t]{3}{*}{$<0.001$} \\
\hline Semi-urban & $17(31.5)$ & $16(29.0)$ & $33(30.3)$ & & \\
\hline Urban & $35(64.8)$ & $14(25.5)$ & $49(45.0)$ & & \\
\hline \multicolumn{6}{|c|}{ Highest educational level } \\
\hline Primary & $0(0.0)$ & $9(16.4)$ & $9(8.3)$ & \multirow[t]{3}{*}{39.772} & \multirow[t]{3}{*}{$<0.001$} \\
\hline Secondary & $2(3.7)$ & $24(43.6)$ & $26(23.9)$ & & \\
\hline Tertiary & $52(96.3)$ & $22(40.0)$ & $74(67.9)$ & & \\
\hline \multicolumn{6}{|l|}{ Main occupation } \\
\hline Trader & $2(3.7)$ & $43(78.2)$ & $45(41.3)$ & \multirow[t]{4}{*}{80.484} & \multirow[t]{4}{*}{$<0.001$} \\
\hline Artisan/ technician & $0(0.0)$ & $4(7.3)$ & $4(3.7)$ & & \\
\hline Civil servant & $37(68.5)$ & $0(0.0)$ & $4(3.7)$ & & \\
\hline Professional & $15(27.8)$ & $8(14.5)$ & $23(21.1)$ & & \\
\hline Monthly income (Nai & & & & & \\
\hline$<30,000$ & $0(0.0)$ & $21(38.2)$ & $21(19.3)$ & 25.538 & $<0.001$ \\
\hline$\geq 30,000$ & $54(100.0)$ & $34(61.8)$ & $88(80.7)$ & & \\
\hline Median income (IQR) & $160000(64000)$ & $60000(40000)$ & $138000(130000)$ & $411.500^{*}$ & $<0.001$ \\
\hline
\end{tabular}

*Mann-Whitney U test 
Table 3. The Costs of Normal Vaginal Delivery among Respondents (Compared among Health Insurance Enrollees and Out-of-Pocket Payers)

\begin{tabular}{|c|c|c|c|c|}
\hline \multirow[t]{3}{*}{ Variable } & Health Insurance Enrollees & Out-of-Pocket Payers & \multirow[t]{3}{*}{ t test } & \multirow[t]{3}{*}{ P-value } \\
\hline & $\mathrm{n}=\mathbf{1 3 0}$ & $\mathrm{n}=\mathbf{1 3 0}$ & & \\
\hline & Mean \pm SD & Mean \pm SD & & \\
\hline \multicolumn{5}{|c|}{ Normal Vaginal Delivery } \\
\hline \multirow[t]{2}{*}{ Direct cost } & $\mathrm{N} 7304.6 \pm 2791.9$ & N30650.8 \pm 18838.3 & \multirow[t]{2}{*}{-13.977} & \multirow[t]{2}{*}{$<0.001$} \\
\hline & $(\$ 19.2 \pm 7.4)^{*}$ & $(\$ 80.6 \pm 49.6)^{*}$ & & \\
\hline \multirow[t]{2}{*}{ Indirect cost } & $\approx 6933.8 \pm 3517.5$ & $¥ 7277.7 \pm 4920.6$ & \multirow[t]{2}{*}{-0.648} & \multirow[t]{2}{*}{0.517} \\
\hline & $(\$ 18.2 \pm 9.3)^{*}$ & $(\$ 19.2 \pm 12.9)^{*}$ & & \\
\hline \multirow[t]{2}{*}{ Total cost } & 丹14238.5 \pm 4809.0 & N37928.5 \pm 19813.0 & \multirow[t]{2}{*}{-13.248} & \multirow[t]{2}{*}{$<0.001$} \\
\hline & $(\$ 34.5 \pm 12.7)^{*}$ & $(99.8 \pm 52.1)^{*}$ & & \\
\hline
\end{tabular}

* = Calculated US Dollar equivalent of the Nigeria Cost Value using the Central Bank of Nigeria exchange rate of $\$ 380$ per dollar as at 23/04/2021.

Table 4. The Costs of Caesarean Delivery among Respondents (Compared among Health Insurance Enrollees and Out-of-Pocket Payers)

\begin{tabular}{|c|c|c|c|c|}
\hline \multirow[t]{3}{*}{ Variable } & Health Insurance Enrollee & Out-of-Pocket Payers & \multirow[t]{3}{*}{ t test } & \multirow[t]{3}{*}{ P-value } \\
\hline & $\mathrm{n}=54$ & $\mathrm{n}=\mathbf{5 5}$ & & \\
\hline & Mean \pm SD & Mean \pm SD & & \\
\hline \multicolumn{5}{|l|}{ C/S Delivery } \\
\hline \multirow[t]{2}{*}{ Direct cost } & $21122.2 \pm 8160.3$ & N82381.8 \pm 53656.5 & \multirow[t]{2}{*}{-8.295} & \multirow[t]{2}{*}{$<0.001$} \\
\hline & $(55.6 \pm 21.5)^{*}$ & $(\$ 216.8 \pm 141.2)^{*}$ & & \\
\hline \multirow[t]{2}{*}{ Indirect cost } & $12653.7 \pm 7207.9$ & N16189.1 \pm 10432.1 & \multirow[t]{2}{*}{-2.062} & \multirow[t]{2}{*}{0.042} \\
\hline & $(\$ 33.3 \pm 19.0)^{*}$ & $(\$ 42.6 \pm 27.5)^{*}$ & & \\
\hline \multirow[t]{2}{*}{ Total cost } & $\$ 33775.9 \pm 10967.5$ & $98570.9 \pm 58349.3$ & \multirow[t]{2}{*}{-8.2022} & \multirow[t]{2}{*}{$<0.001$} \\
\hline & $(88.9 \pm 28.9)^{*}$ & $(\$ 259.4 \pm 153.6)^{*}$ & & \\
\hline
\end{tabular}

* = Calculated US Dollar equivalent of the Nigeria Cost Value using the Central Bank of Nigeria exchange rate of $\$ 380$ per dollar as at 23/04/2021.

Table 5. Willingness to Uptake Health Insurance by non-enrollees (OOP Payers)

\begin{tabular}{|l|l|l|}
\hline Variable & Frequency N=370 & Percentage (\%) \\
\hline Willingness to enroll into the Health Insurance Scheme & \multicolumn{2}{l}{} \\
\hline Yes & 348 & 94.1 \\
\hline No & 22 & 5.9 \\
\hline If YES, when (n= 348) & \multicolumn{2}{|l|}{} \\
\hline Immediately now & 44 & 12.6 \\
\hline Later after discussing with my family & 253 & 72.7 \\
\hline At my next visit & 51 & 14.7 \\
\hline If NO, why (n= 22) & \multicolumn{2}{|l|}{} \\
\hline Still not convinced & 6 & 27.3 \\
\hline Do not have the money & 11 & 50.0 \\
\hline Hardly attend hospitals and do not plan to deliver again & 5 & 22.7 \\
\hline
\end{tabular}




\section{Conclusion}

The costs of vaginal and caesarean section deliveries are lower among the Health Insurance enrollees than the Out-of-Pocket payers. The difference in the cost was majorly in the direct cost of medical care which health insurance aims to achieve. This study also found that majority of the non-insurance enrollees and out-of-pocket payers are willing to take up health insurance though after

\section{References}

[1] Nahar S, Costello, A. The hidden cost of 'free' maternity care in Dhaka, Bangladesh. Health Policy and Planning. 1998; 13(4): 417 - 422. Oxford University Press 1998.

[2] Simkhada P, Teijlingen EV, GauSharma G, Simkhada B, Townend J. User costs and informal payments for care in the largest maternity hospital in Kathmandu, Nepal. Health Science Journal. 2012; 6(2): 317-334.

[3] Sambo MN, Abdulrazaq GA, Shamang, AF, Ibrahim AA. Household cost of antenatal care and delivery services in a rural community of Kaduna state, Northwest Nigeria. Niger Med Journal. 2013; 54(2): 87-91.

[4] FGN. Federal Government of Nigeria. Workshop for Nigerian actors on improving financial access to Maternal, Newborn, Child Health (MNCH) services for the Poor in Nigeria. Technical Report. Tinapa Calaba. 2016; Pg 1-64.

[5] Kalu-Umeh NN, Sambo MN, Idris SH, Kurfi AM. Costs and Patterns of Financing Maternal Health Care Services in Rural Communities in Northern Nigeria: Evidence for Designing National Fee Exemption Policy. International Journal of MCH and AIDS. 2013; 2(1): 163-172.

[6] WHO. World Health Organization. Social Health Insurance: Sustainable health Financing, Universal Coverage and Social health Insurance. Fact sheet No 320. 2005. Available from: http://www.who.int/ha. [Last accessed on February 2021].

[7] Adeniran AS, Aun II, Fawole AA, Aboyeji AP. Comparative analysis of caesarean delivery among discussing with their family. Therefore, interventions to increase awareness on health insurance, show case its benefit over out-ofpocket payments and eliminate myths and misconceptions about the health insurance scheme are recommended to increase uptake.

\section{Competing Interest}

The authors declare no competing or conflict of interest.

out-of-pocket and health insurance clients in Ilorin. Nigeria. Niger Postgrad Med J. 2020; 27: 108-14.

[8] Aregbesola, B. Healthcare in Nigeria: Challenges and recommendations. Sociialprotection.org. 2020.

Available online at http://sociialprotection.org/discover/blog/healthcare-nigeria-challenges-and-recommendations.

[9] Aderibigbe SA, Wit FW, van Hensbroek MB, Osagbemi G.K, Akande TM. The effect of health insurance on maternal and child health: A systematic review. J Med Trop. 2018; 20: 83-92.

[10]Roberts AA, Agboola BC, Oshunniyi L, Roberts OY. Health Insurance and User Fees: A Survey of Health Service Utilization and Payment Methods in Mushin LGA, Lagos, Nigeria. Ann Med Health Sci Res. 2018; 8: 93-99.

[11] Youngji JO, Alland K, Ali H, Mehra S, LeFevre ME, Pak SE, et al. Antenatal care in rural Bangladesh: current state of costs, content and recommendations for effective service delivery. BMC Health Services Research. 2019; 19: 861-872. https://doi.org/10.1186/s12913-019-4696-7.

[12] Callender E, Shand A, Ellwood D, Fox H, Nassar N. Financing Maternity and Early Childhood Healthcare in The Australian Healthcare System: Costs to Funders in Private and Public Hospitals Over the First 1000 Days. Int J Health Policy Manag. 2020; $\quad x(x)$ : 1-10. doi 10.34172/ijhpm.2020.68.

[13]Borghi J, Bastus S, Belizan M, Carroli G, Hutton G, Fox-Rushby J. 2003. Costs of Publicly Provided Maternity Services in Rosario, Argentina. Salud pública de méxico. 2003; 45(1): 27-34. 
[14]Bonu S, Bhushan I, Rani M, Anderson I Incidence and correlates of 'catastrophic' maternal health care expenditure in India. Health Plann Policy 2009; 24: 445-56.

[15] Govil D, Purohit N, Gupta SD, Mohanty SK. Out-of-pocket expenditure on prenatal and natal care post Janani Suraksha Yojana: a case from Rajasthan, India. Journal of Health, Population and Nutrition. 2016; 35: 15- 46.

[16]Zaman S, Khan A. Costs of vaginal delivery and caesarean section at a tertiary level public hospital in Islamabad, Pakistan. BMC Pregnancy and Childbirth. 2010; 10(2): 1-8.

[17] Mukherjee S, Singh A. Has the Janani Suraksha Yojana (a conditional maternity benefit transfer scheme) succeeded in reducing the economic burden of maternity in rural India? Evidence from the Varanasi district of Uttar Pradesh. Journal of Public Health Research. 2018; (7): 957-963.

[18]Awoyemi, BO. The Rate and Costs of Caesarean Section among Women in Ado-Ekiti, Nigeria. Health Econ Outcome Res Open Access.2020; 6(3): 001-005.

[19] Sarker AR, Sultana M, Ali N, Akram R, Sheikh $\mathrm{N}$, Mahumud R A, et al. Cost comparison and determinants of out-of- pocket payments on child delivery care in Bangladesh. Int $\mathbf{J}$ Health Plann Mgmt. 2018; 1-18.

[20] Odhiambo J, Ruhumuriza J, Nkurunziza T, Riviello R, Shrime M, Lin Y, et al. Health Facility
Cost of Caesarean Delivery at a Rural District Hospital in Rwanda Using Time-Driven ActivityBased Costing. Maternal and Child Health Journal. 2019. 1-7. https://doi.org/10.1007/s10995-018-2674$\mathrm{Z}$

[21]Ekiti State Government. History of Ekiti State. (2016) Available at http://ekitistate.gov.ng. [Last Accessed on January 2, 2021].

[22]Federal Teaching Hospital Ido-Ekiti. Available at www.fethi.gov.ng (Last accessed, January 2021). [23]WHO. World Health Organization. Health Systems Financing: The Path to Universal Coverage. Geneva. 2010; 1-50.

[24] Mbuli MD, Awolu MM, Asangbeng TE., Mbuli IA, Pangmekeh PJ, Shey ND. The Influence of Health Insurance on the Utilization of Maternal Health Care Services in Kumba Health District: A Community-based Assessment. BioRxiv; 2018; 118. doi: https://doi.org/10.1101/474130.

[25] Matsubara C, Nguyen TA, Murakami H. Exploring affordability and healthcare-seeking behaviour for delivery and antenatal care among the poor and ethnic minorities in rural Northwestern Vietnam. Global Health Action. 2019; 12: 1-9 DOI: 10.1080/16549716.2018.1556573.

[26] Goli S, Rammohan A, Moradhvaj I: Out-ofpocket expenditure on maternity care for hospital births in Uttar Pradesh, India. Health Economics Review Springer, Heidelberg. 2018; 8(5): 1-16. http://dx.doi.org/10.1186/s13561-018-0189-3. 